\title{
CKD 5D Asia-what is common and what is different from the West?
}

\author{
Kunitoshi Iseki
}

\begin{abstract}
The mission of Kidney Disease: Improving Global Outcomes (KDIGO) is to improve the care and outcomes of kidney disease patients worldwide through the development and implementation of global clinical practice guidelines (CPG). To attain this mission, KDIGO has been publishing CPGs since 2008. Implementation of CPGs is very important, in particular for many developing countries in Asia. This review was written after the first implementation summit of "chronic kidney disease (CKD)-mineral bone disorder (MBD) guideline in Asia" which took place on April 28 to 29, 2018 , in Tokyo.

Prevalence of end-stage renal disease (ESRD) is increasing rapidly in Asia. CKD-MBD is a modifiable risk factor of cardiovascular disease (CVD), bone fracture, and mortality, both non-dialysis-dependent and dialysis patients. Concept of CKD-MBD is a newly developed, and the CKD-MBD CPG was published on 2009 and updated on 2017. Unfortunately, very few evidences are available to recommend for daily practice. Many treatment options are based on expert suggestion. Incidence of ESRD especially diabetes mellitus (DM) is very high in Asian countries. More research is needed, in particular using patient-reported outcomes (PRO).
\end{abstract}

Keywords: Survival, Clinical practice guideline, CKD, KDIGO, CKD-MBD

\section{Background}

The mission of Kidney Disease: Improving Global Outcomes (KDIGO) is to improve the care and outcomes of kidney disease patients worldwide through the development and implementation of global clinical practice guideline (CPG) [1]. To attain this mission, KDIGO has published 11 CPGs since 2008 [2-12] (Table 1). More than 30 controversy conferences $(C C)$ were held in many cities worldwide. Core KDIGO efforts are to run the cycle of CC, CPG, implementation, research, clinical practice conference (CPC), and revision and updates. Recent KDIGO implementation activities are summarized in Table 2. Implementation of CPGs is very important, in particular for many developing countries in Asia. KDIGO joint symposiums (CPC) are currently organized with each national or regional society, Asian Pacific Society of Nephrology (APSN), American Society of Nephrology (ASN), and International Society of Nephrology (ISN).

Correspondence: chihokun_ohra@yahoo.co.jp

Clinical Research Support Center, Nakamura Clinic, Iso 4-2-1, Urasoe, Okinawa, Japan

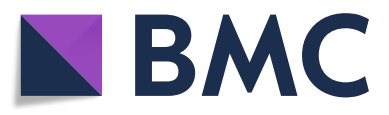

(c) The Author(s). 2018 Open Access This article is distributed under the terms of the Creative Commons Attribution 4.0 International License (http://creativecommons.org/licenses/by/4.0/), which permits unrestricted use, distribution, and

reproduction in any medium, provided you give appropriate credit to the original author(s) and the source, provide a link to the Creative Commons license, and indicate if changes were made. The Creative Commons Public Domain Dedication waiver (http://creativecommons.org/publicdomain/zero/1.0/) applies to the data made available in this article, unless otherwise stated. 
Table 1 Clinical practice guideline by KDIGO

\author{
1. Hepatitis C in CKD: 2008 \\ 2. CKD mineral and bone disorder (CKD-MBD): 2009 \\ 3. Care of kidney transplant recipients: 2009 \\ 4. Acute kidney injury (AKI): 2012 \\ 5. Anemia in CKD: 2012 \\ 6. Glomerulonephritis (GN): 2012 \\ 7. Blood pressure in CKD: 2012 \\ 8. CKD evaluation and management: 2013 \\ 9. Lipids in CKD: 2013 \\ 10. Living kidney donors: 2017 \\ 11. CKD mineral and bone disorder (CKD-MBD): updated 2017
}

of ESKD requiring RRT have decreased gradually between 2008 and 2012, except among men aged $\geq 80$ years in Japan [19]. Recent activities of the Japanese Society of Nephrology (JSN) and other related societies may have contributed for this improvement. Moreover, JSN is collaborating with ISN to advance the knowledge worldwide towards the eradication of kidney disease and to promote all types of related activities that facilitate the spread of awareness, diagnosis, and treatment of kidney disease [20]. However, people live longer and also dialysis patients [21], the number of aged population is increasing, and therefore, the prevalence of ESRD is continuously increasing in Japan, at least several years more.

\section{Survival of dialysis patients}

The Japanese Society for Dialysis Therapy (JSDT) has been conducting nationwide survey on dialysis facilities and patients since 1983. According to the annual report of JSDT, the annual crude mortality rates have been stable at around 9.5\%, even though there is a rapid increase in the number of patients: 37,000 (1983) to 320,000 (2015). As the prevalence of DM and mean age of prevalent patients are increasing, overall mortality risk should be decreasing. The response rates have been stable at around 97\% except in 1989 which was less than $90 \%$ due to the miss-conduct of the JSDT. JSDT has

\section{Table 2 Recent KDIGO implementation activities}

1. Dissemination of printed guideline supplements at major nephrology Congresses from the KDIGO booth in exhibit hall

2. Translations - multiple language translations of both full text and executive summary

3. Educational Symposia-live, expert presentations on KDIGO guidelines, usually held in collaboration with local, regional, or international nephrology societies to explain the recommendations and science behind them

4. Implementation tools - development of educational materials based on KDIGO guidelines, including speaker's guides, reference tools, and webinars

5. Implementation summits - a new KDIGO program designed to help implement a KDIGO guideline in a specific region or country, taking into account local issues such as insurance, reimbursement policies, and local guidelines

6. KDIGO app-access to all KDIGO guidelines on the Smartphone app, available for free download from the iTunes Store and Google Play
Table 3 Key messages of the updated KDIGO CKD-MBD guideline (cited from the KDIGO speaker's guide)

1. Prospective studies evaluating BMD testing in adults with CKD represent a substantial advance since the original guideline from 2009, making a reasonable case for BMD testing if the results will impact future treatment. 2. It is important to emphasize the interdependency of serum calcium, phosphate, and PTH for clinical therapeutic decision-making.

3. Phosphate-lowering therapies may only be indicated in the case of "progressive or persistent hyperphosphatemia".

4. New evidence suggests that excess exposure to exogenous calcium in adults may be harmful in all severities of CKD, regardless of other risk markers.

5. It is reasonable to limit dietary phosphate intake, when considering all sources of dietary phosphate (including "hidden" sources).

6. The PRIMO* and OPERA** studies failed to demonstrate improvements in clinically relevant outcomes but did demonstrate increased risk of hypercalcemia. Accordingly, routine use of calcitriol or its analogs in CKD G3a-G5 is no longer recommended.

7. No consensus was reached to recommend cinacalcet as first-line therapy for lowering PTH in all patients with SHPT and CKD G5D.

*PRIMO study [15]

**OPERA study [16]

published many papers written in English such as clinical practice guidelines, proposals, and guides [22-39].

Dialysis Outcomes and Practice Pattern Study (DOPPS) is a prospective observational, international collaborative study [40]. According to the DOPPS, adjusted survival in Japan is better than that of the Europe and USA [41, 42]. So far, there is no clear-cut explanation for this observation [43] although overall mortality risk has been decreased significantly in the USA [44]. According to the DOPPS, several unique practice patterns in Japan were noted. This practice pattern is the long-term tradition of Japanese dialysis physicians, nurses, technicians, and others. We defined "conventional HD is $4 \mathrm{~h}$, three times per week" in 2015 [34]. Many Japanese are quite punctual. Regular visits to the bed-side by physician and nurses also contribute to the early detection of symptoms and signs of dialysis complication. I believe the adherence to this practice of "conventional HD" is one of the key factors explaining the better survival in Japan [45]. However, as aged HD patients are increasing, demands for life support such as diet and transportation are increasing and become a social burden. Compared to the general population, dialysis patients seem to be plus 15 to 20 years of their calendar age. Further studies are necessary to understand the life expectancy gains in ESRD patients [46].

Better management of secondary hyperparathyroidism may retard the progression of complication related to CKD-MBD [47]. Regarding the CKD-MBD GLs and treatment, new drugs come. GL comes later. Even KDIGO2017 information on ferric citrate or etelcalcetide have not included. Generally speaking, even though treatment is recommended based on randomized control trial (RCT), we have to be careful when applying to individual patient. There may be racial differences in side-effects. In JSDT, 
there are two GLs on CKD-MBD written in English [24, 32]. The suggested target of intact PTH was $60-180 \mathrm{pg} /$ $\mathrm{ml}$ [24] and updated to $60-240 \mathrm{pg} / \mathrm{ml}$ [32] lower than that of the West (up to nine times higher than the upper limit). Again, there may be racial differences in interdependency in $\mathrm{Ca}, \mathrm{Pi}$, and $\mathrm{PTH}$.

\section{Clinical research}

Several years ago, interesting debate was published [48]. As noted, dialysis therapy has been conducted by experience-based medicine as associated with very few RCT [49]. Possible explanation for this observation may be related to too many factors related to high mortality among dialysis patients. Firstly, they should be managed under "conventional HD." Unless otherwise, there would be no drugs to replace the dialysis itself.

In the Nephrology subspecialty, the number of RCT has been the lowest among many subspecialties. In non-CKD patients, there was a problem of "outcome." Incidence of "hard outcomes" such as death or ESRD is relatively low; therefore, it requires many subjects and long-term follow-up. It has been difficult for pharmaceutical companies to support RCT. Recently, a decline rate of eGFR has been proposed as a surrogate marker of CKD outcome [50, 51]. Fortunately, data for eGFR by using Japanese formula [52] is broadly available for general screening and many medical facilities in Japan. Change in proteinuria is also helpful as a surrogate marker of CKD outcome [53]. In the near future, the number of RCT may increase in nephrology field. But, for dialysis patients, there would be no such surrogate marker, so far.

Currently, shift in the research focus is proposed [54]. They suggested (1) more qualitative methods used in social sciences, (2) more PRO, (3) unmet needs for studies to elucidate racial and ethnic differences in quality of life (QOL) issues, (4) research and policy changes should be driven by experienced practitioners with current patient contact to ensure that they are relevant to patient needs, (5) support research to improve QOL and discourage cookie-cutter survival studies, and (6) QOL metrics (pain, depression) needs to be incentivized in clinical practice to drive-related research efforts. The 36-Item Short-Form Health Survey (SF-36) and EuroQol 5 Dimension (EQ-5D) are candidate tools for PRO. In the field of rheumatology, PRO is frequently used to evaluate the efficacy of new drugs. Moreover, multidimensional measure of dialysis was proposed [55]. In dialysis patients, there are a lot of clinical measures including PRO. Then, we will see the relationship between these measures and dialysis strategies and with QOL and survival of dialysis patients. This process has been practiced by experienced practitioners with frequent patient contact.
RCTs provide the most reliable evidence about the safety and effectiveness of interventions to improve health care and patient outcomes. Unfortunately, the potential for trials to inform treatment decisions remains limited because the outcomes reported often do not resonate with what is directly meaningful and relevant to patients and their clinicians. Recently, initiative for standardized outcomes in Nephrology (SONG) was proposed [56]. Outcome reporting bias exists as it is not uniformly defined. They report on the basis of favorable results. Such problems may undermine the reliability of published trials, leading to inefficient use of scarce research and health care resources and unintended harm to patients.

Muscle and fat wasting may develop in CKD, in particular elderly, and exacerbated by decreasing kidney function, coexisting conditions and frailty. Protein-energy wasting (PEW) is common in dialysis patients, and dietary management is difficult in such patients. Dietary habits and lifestyle vary widely by cultural, socio-economic, and racial background. Diagnostic criteria of PEW were proposed in 2008 [57]. Additional studies that are patient centered and cost-effective are needed to ensure a more robust, evidence-based approach to the nutritional management of CKD [58].

\section{Conclusions}

Due to the small number of RCT in Nephrology, CPG is largely based on expert opinion and observational studies. In this regard, more research on PRO and socio-economic factors is required to prevent the incidence and progression of CKD and improve the life expectancy. Currently, there are several cohort studies from nationwide general screening program [59, 60], CKD cohort [61], and dialysis patients [62,63] in Japan. CKD-MBD Asia summit by KDIGO was the first to discuss such issues. Management for CKD-MBD is rapidly changing as new drugs appear in the market [64].

KDIGO is currently working to response to the proposal from SONG with the glomerulonephritis (GN) guideline. GN is still the leading cause of ESRD in some Asian countries $[65,66]$. Stakeholders such as patients, clinicians, and policymakers need to be involved for the decision-making.

\section{Abbreviations}

APSN: Asian Pacific Society of Nephrology; ASN: American Society of Nephrology; CC: Controversy conference; CKD: Chronic kidney disease; CPC: Clinical practice conference; CPG: Clinical practice guideline; CVD: Cardiovascular disease; DM: Diabetes mellitus; DOPPS: Dialysis Outcomes and Practice Patterns Study; EQ-5D: EuroQol 5 Dimension; ESRD: End-stage renal disease; ISN: International Society of Nephrology; JSDT: Japanese Society for Dialysis Therapy; JSN: Japanese Society of Nephrology; KDIGO: Kidney Disease: Improving Global Outcomes; MBD: Mineral bone disorder; PEW: Protein-energy wasting; PRO: Patientreported outcomes; QOL: Quality of life; RCT: Randomized control trial; SF36: 36-Item Short-Form Health Survey; SONG: Standardized outcomes in Nephrology; USRDS: United States Renal Data System 


\section{Author's contributions}

The author read and approved the final manuscript.

\section{Author's information}

The author is an executive committee member of the KDIGO (2017-2019).

Ethics approval and consent to participate

Not applicable.

\section{Consent for publication}

Not applicable.

\section{Competing interests}

The author declare that he has no competing interests.

\section{Publisher's Note}

Springer Nature remains neutral with regard to jurisdictional claims in published maps and institutional affiliations.

\section{Received: 13 June 2018 Accepted: 1 August 2018}

Published online: 12 September 2018

\section{References}

1. Eckardt KU, Kasiske BL. Kidney disease: improving global outcome. Nat Rev Nephrol. 2009;5:650-7.

2. Kidney Disease: Improving Global Outcomes (KDIGO). KDIGO clinical practice guidelines for the prevention, diagnosis, evaluation, and treatment of hepatitis C in chronic kidney disease. Kidney Int Suppl. 2008;73(109):S199 .

3. Kidney Disease: Improving Global Outcomes (KDIGO) Transplant Work Group. KDIGO clinical practice guidelines for the care of kidney transplant recipients. Am J Transplant. 2009;9(Suppl 3):S1-S157.

4. Kidney Disease: Improving Global Outcomes (KDIGO) CKD-MBD Work Group. KDIGO clinical practice guidelines for the diagnosis, evaluation, prevention, and treatment of chronic kidney disease (CKD-MBD). Kidney Int. 2009;76(Suppl 113):S1-S130.

5. Kidney Disease: Improving Global Outcomes (KDIGO) Blood Pressure Work Group. KDIGO clinical practice guidelines for the Management of Blood Pressure in Chronic Kidney Disease. Kidney Int. 2012;2:337-414.

6. Kidney Disease: Improving Global Outcomes (KDIGO) Glomerulonephritis Work Group. KDIGO clinical practice guidelines for glomerulonephritis. Kidney Int. 2012;2(Suppl 2):139-274.

7. Kidney Disease: Improving Global Outcomes (KDIGO) Anemia Work Group. $\mathrm{KDIGO}$ clinical practice guidelines for anemia in chronic kidney disease. Kidney Int. 2012;2:279-335.

8. Kidney Disease: Improving Global Outcomes (KDIGO) Acute Kidney Injury Work Group. KDIGO clinical practice guidelines for acute kidney injury. Kidney Int. 2012:2:1-138.

9. Kidney Disease: Improving Global Outcomes (KDIGO) Work Group. KDIGO clinical practice guidelines for the evaluation and management of chronic kidney disease. Kidney Int Suppl. 2013;3:1-150.

10. Kidney Disease: Improving Global Outcomes (KDIGO) Lipid Work Group. KDIGO clinical practice guidelines for lipid management in chronic kidney disease. Kidney Int. 2013;3:259-305.

11. Kidney Disease: Improving Global Outcomes (KDIGO) Living Donor Work Group. KDIGO clinical practice guidelines on the evaluation and care of living kidney donors. Transplantation. 2017;101(8S):S1-S109.

12. Kidney Disease: Improving Global Outcomes (KDIGO) CKD-MBD Update Work Group. KDIGO2017 clinical practice guidelines update for the diagnosis, evaluation, prevention, and treatment of chronic kidney disease mineral and bone disorder (CKD-MBD). Kidney Int. 2017;76(Suppl 7):1-59.

13. Moe S, Drüeke T, Cunningham J, et al. Definition, evaluation, and classification of renal osteodystrophy: a position statement from Kidney Disease: Improving Global Outcomes (KDIGO). Kidney Int. 2006;69(11):1945-53.

14. Moe SM, Drüeke T, Lameire N, Eknoyan G. Chronic kidney disease-mineralbone disorder: a new paradigm. Adv Chronic Kidney Dis. 2007;14:3-12.

15. Thadhani $R$, Appelbaum E, Pritchett $Y$, et al. Vitamin D therapy and cardiac structure and function in patients with chronic kidney disease: the PRIMO randomized controlled trial. JAMA. 2012;307:674-84.

16. Wang AY, Fang F, Chan J, et al. Effect of paricalcitol on left ventricular mass and function in CKD--the OPERA trial. J Am Soc Nephrol. 2014;25(1):175-86.
17. The EVOLVE Trial Investigators. Effect of cinacalcet on cardiovascular disease in patients undergoing dialysis. N Engl J Med. 2012;367(26):2482-94.

18. Saran R, Robinson B, Abbott KC, et al. US Renal Data System 2017 Annual Data Report: Epidemiology of Kidney Disease in the United States. Am J Kidney Dis. 2018;71(3S1):S1-S672.

19. Wakasugi M, Kazama JJ, Narita I. Anticipated increase in the number of patients who require dialysis treatment among the aging population of Japan. Ther Apher Dial. 2015;19:201-2016.

20. Kashihara N, Nangaku M, Ito S, et al. The Sendai declaration for the eradication of kidney disease. Clin Exp Nephrol. 2018;22(1):1-2.

21. Wakasugi M, Kazama JJ, Narita I. Mortality trends among Japanese dialysis patients, 1988-2013: a joinpoint regression analysis. Nephrol Dial Transplant. 2016;31(9):1501-7.

22. Gejyo F, Saito A, Akizawa T, et al. 2004 Japanese Society for Dialysis Therapy guidelines for renal anemia in chronic hemodialysis patients. Ther Apher Dial. 2004;8:443-59.

23. Ohira S, Naito H, Amano I, et al. 2005 Japanese Society for Dialysis Therapy Guidelines for vascular access construction and repair for chronic hemodialysis. Ther Apher Dial. 2006;10:449-62.

24. Guideline Working Group, Japanese Society for Dialysis Therapy. Clinical practice guideline for the management of secondary hyperparathyroidism in chronic dialysis patients. Ther Apher Dial. 2008;12:514-25.

25. Tsubakihara Y, Nishi S, Akiba T, et al. 2008 Japanese Society for Dialysis Therapy: guidelines for renal Anemia in chronic kidney disease. Ther Apher Dial. 2010;14:240-75.

26. Kawanishi H, Akiba T, Masakane I, et al. Standard on microbiological management of fluids for hemodialysis and related therapies by the Japanese Society for Dialysis Therapy 2008. Ther Apher Dial. 2009;13:161-6.

27. Working Group Committee for the Preparation of Guidelines for Peritoneal Dialysis, Japanese Society for Dialysis Therapy. 2009 Japanese Society for Dialysis Therapy guidelines for peritoneal dialysis. Ther Apher Dial. 2010;14: 489-504.

28. Hirakata H, Nitta K, Inaba M, et al. Japanese Society for Dialysis Therapy guidelines for management of cardiovascular disease in patients on chronic hemodialysis. Ther Apher Dial. 2012;16:387-435.

29. Akiba T, Hora K, Imawari M, et al. 2011 Japanese Society for Dialysis Therapy guidelines for the treatment of hepatitis $C$ virus infection in dialysis patients. Ther Apher Dial. 2012;16:289-310.

30. Masakane I, Kawanishi H, Mineshima M, et al. 2011 JSDT standard on the management of endotoxin retentive filter for dialysis and related therapies. Ther Apher Dial. 2013;17:229-40.

31. Kukita K, Ohira S, Amano I, et al. 2011 update Japanese Society for dialysis therapy guidelines of vascular access construction and repair for chronic hemodialysis. Ther Apher Dial. 2015;19(Supplement 1):1-39.

32. Fukagawa M, Yokoyama K, Koiwa F, et al. Clinical practice guideline for the management of chronic kidney disease-mineral and bone disorder. Ther Apher Dial. 2013;17:247-88.

33. Nakao T, Inaba M, Abe M, et al. Best practice for diabetic patients on hemodialysis 2012. Ther Apher Dial. 2015:19(Supplement 1):40-66.

34. Watanabe $Y$, Kawanishi H, Suzuki K, et al. Japanese Society for Dialysis Therapy Clinical Guideline for "maintenance hemodialysis: hemodialysis prescriptions". Ther Apher Dial. 2015;19(Suppl 1):67-92.

35. Watanabe $Y$, Yamagata K, Nishi S, et al. Japanese society for dialysis therapy clinical guideline for "hemodialysis initiation for maintenance hemodialysis: hemodialysis prescriptions". Ther Apher Dial. 2015;19(Supplement 1):93-107.

36. Watanabe $Y$, Hirakata H, Okada K, et al. Proposal for the shared decisionmaking process regarding initiation and continuation of maintenance hemodialysis. Ther Apher Dial. 2015;19(Supplement 1):108-17.

37. Yamamoto H, Nishi S, Tomo T, et al. 2015 Japanese Society for Dialysis Therapy: guidelines for renal anemia in chronic kidney disease. Ren Replace Ther. 2017:3:36.

38. Nitta K, Masakane I, Tomo T, et al. Policy for developing clinical practice guidelines of Japanese Society for Dialysis Therapy. Ren Replace Ther. 2017;3:34

39. Mineshima M, Kawanishi H, Ase T, et al. 2016 update Japanese Society for Dialysis Therapy Standard of fluids for hemodialysis and related therapies. Ren Replace Ther. 2018:4:15.

40. Pisoni TL, Gillespie BW, Dickinson DM, et al. The Dialysis Outcomes and Practice Patterns Study (DOPPS): design, data elements, and methodology. Am J Kidney Dis. 2004;44(5 Suppl 2):7-15.

41. Goodkin DA, Bragg-Gresham JL, Koenig KG, et al. Association of comorbid conditions and mortality in hemodialysis patients in Europe, Japan, and the 
United States: the Dialysis Outcomes and Practice Patterns Study (DOPPS). J Am Soc Nephrol. 2003;14:3270-7.

42. Goodkin DA, Young EW, Kurokawa K, et al. Mortality among hemodialysis patients in Europe, Japan, and the United States: case-mix effects. Am J Kidney Dis. 2004;44(Suppl 2):S16-21.

43. Robinson BM, Akizawa $\mathrm{T}$, Jager $\mathrm{KJ}$, et al. Factors affecting outcomes in patients reaching end-stage kidney disease worldwide: differences in access to renal replacement therapy, modality use, and haemodialysis practices. Lancet. 2016;388(10041):294-306.

44. Foster JB, Mitsnefes MM, Dahhou M, et al. Changes in excess mortality from end-stage renal disease in the United States from 1995-2013. Clin J Am Soc Nephrol. 2018;13:91-9.

45. Iseki K, Shinzato T, Nagura Y, et al. Factors influencing long-term survival in patients on chronic dialysis. Clin Exp Nephrol. 2004;8:89-97.

46. Johansen KL. Life expectancy gains for patients with ESRD. Clin J Am Soc Nephrol. 2018;13:11-2.

47. Komaba H, Fukagawa M. Secondary hyperparathyroidism and proteinenergy wasting in end-stage renal disease. Ther Apher Dial. 2018; (in press)

48. Van Biesen W, Lameire N. Moderator's view: Are alternative dialysis strategies superior to conventional dialysis: what Popper tells us... Nephrol Dial Transplant. 2013;28:837-8.

49. Archdeacon P, Shaffer RN, Winkelmayer WC, et al. Fostering innovation, advancing patient safety: the kidney health initiative. Clin J Am Soc Nephrol. 2013;8(9):1609-17.

50. Coresh J, Turin TC, Matsushita $\mathrm{K}$, et al. Decline in estimated glomerular filtration rate and subsequent risk of end-stage renal disease and mortality. JAMA. 2014;311(24):2518-31.

51. Kanda E, Usui T, Kashihara N, et al. Importance of glomerular filtration rate change as surrogate endpoint for the future incidence of end-stage renal disease in general Japanese population: community-based cohort study. Clin Exp Nephrol. 2018;22:318-27.

52. Matsuo S, Imai E, Horio M, et al. Revised equations for estimated GFR from serum creatinine in Japan. Am J Kidney Dis. 2009;53(6):982-92.

53. Usui T, Kanda E, Iseki C, et al. Observation period for changes in proteinuria and risk prediction of end-stage renal disease in general population. Nephrology. (in press)

54. Perl J, Dember LM, Bargman JM, et al. The use of a multidimensiona measure of dialysis adequacy-moving beyond small solute kinetics. Clin J Am Soc Nephrol. 2017;12:839-47.

55. Lee MB, Bargman JM. Survival by dialysis modality-who cares? Clin J Am Soc Nephrol. 2016;11:1083-7.

56. Tong A, Craig JC, Nagler EV, Biesen WV. Composing a new song for trials: the Standardized Outcomes in Nephrology (SONG) initiative. Nephrol Dial Transplant. 2017:32:1963-6.

57. Fouque D, Kalanta-Zadeh K, Kopple J, et al. A proposed nomenclature and diagnostic criteria for protein-energy wasting in acute and chronic kidney disease. Kidney Int. 2008;73:391-8.

58. Kalantar-Zadeh K, Fouque D. Nutritional management of chronic kidney disease. N Engl J Med. 2017;377:1765-76.

59. Iseki K, Asahi K, Moriyama T, et al. Risk factor profiles based on estimated glomerular filtration rate and dipstick proteinuria among participants of the Specific Health Check and Guidance System in Japan 2008. Clin Exp Nephrol. 2012;16:244-9.

60. Iseki K, Asahi K, Yamagata K, et al. Mortality risk among screened subjects of the specific health check and guidance program in Japan 2008-2012. Clin Exp Nephrol. 2017;21 (6):978-85.

61. Hoshino J, Nagai K, Kai H, et al. A nationwide prospective cohort study of patients with advanced chronic kidney disease in Japan: the Reach-J CKD cohort study. Clin Exp Nephrol. 2018;22(2):309-17.

62. Matsukuma Y, Tanaka S, Taniguchi M, et al. Association of geriatric nutritional risk index with infection-related mortality in patients undergoing hemodialysis: the Q-Cohort Study. Clin Nutr. 2018; (in press)

63. Komaba H, Kakuta T, Wada T, et al. Nutritional states and survival of maintenance hemodialysis patients receiving lanthanum carbonate. Nephrol Dial Transplant. 2018; (in press)

64. Fukagawa M, Inaba M, Yokoyama K, et al. An introduction to CKD-MBD research: restart for the future. Clin Exp Nephrol. 2017;21(Suppl 1):S1-3.

65. Imai E, Matsuo S. Chronic kidney disease in Asia. Lancet. 2008;371:2147-8.

66. Wang J, Zhang L, Tang SC, et al. Disease burden and challenges of chronic kidney disease in North and East Asia. Kidney Int. 2018; (in press)

\section{Ready to submit your research? Choose BMC and benefit from:}

- fast, convenient online submission

- thorough peer review by experienced researchers in your field

- rapid publication on acceptance

- support for research data, including large and complex data types

- gold Open Access which fosters wider collaboration and increased citations

- maximum visibility for your research: over $100 \mathrm{M}$ website views per year

At BMC, research is always in progress.

Learn more biomedcentral.com/submissions 